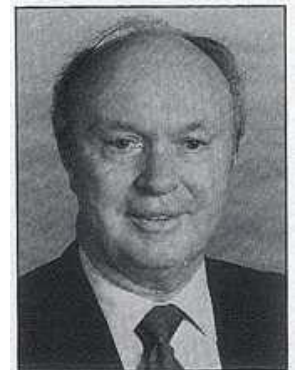

KENNETH R. FARRELL

Vice President

Agriculture and Natural Resources

\title{
Publicly funded agricultural research: an impending crisis?
}

For more than a century, taxdollars spent on agricultural research have produced some of society's highest net returns, up to $45 \%$ a year according to studies by economists.* Scientists at land-grant universities and the U.S. Department of Agriculture have improved farm efficiency, leading to an abundance of low-cost food and a positive balance in international trade. U.S. research-based information and technology and U.S.-trained foreign agricultural scientists have also provided the foundation for a quantum increase in vorld food production over the past 30 years.

Moreover, the application of science to agricultural production, food processing, and manufacturing has by no means run its course. Advances in basic biology, for example, are spawning a vast array of potential plant and animal production technologies. Resulting productivity gains may dwarf those of the past century - while enhancing environmental quality and natural resourcemanagement.

Despite its past success and future promise, funding for agricultural research is endangered at both the state and federal levels. Currently, 33 of the 50 states are running substantial budget deficits, leaving university and, in turn, agricultural research funding in jeopardy. California slashed its 1990-91 funding of agricultural research by $5 \%$; further cuts are likely for 1991-92.

State supportmakes up about two-thirds of the total budget of the UCAgricultural ExperimentStation (AES) - an amount that equals less than $1 \%$ of the state's gross farm income. During the 1980s, the combined effects of inflation and escalating costs of instrumentation to conduct increasingly complex research have resulted in a severe erosion, perhaps $50 \%$ to $60 \%$ in real terms, in the non-salary components of the AES budget.

Federal support of experiment station research through the USDA, which accounts for another 19\% of the UC Agricultural Experiment Station budget, was no better. "Formula funding," constituting nearly $60 \%$ of all USDA-originated funding for state experiment stations, eroded by $20 \%$ in inflation-adjusted terms during the 1980s. Relative to all non-defense R\&D expenditures by the federal government, spending on agricultural research has declined from $13 \%$ in 1955 to only $4 \%$ in 1990.

Despite the highly promising USDA National Research Initiative established in 1990, which eventually could make as much as $\$ 500$ million available annually on a competitive basis, long-term prospects for federal support are clouded. Huge federal budget deficits loom into the indefinite future. High priority likely will be given to $R \& D$ in the fields of medicine, space, energy, and environment. Total federal spending for agricultural research may well be a zero-sum game in the $1990 \mathrm{~s}$ - an increase in one part of the agricultural research budget may be a reduction in another part of that budget.

The onemajor source of increased funding for experiment station scientists during the past decade has been in the basic sciences through organizations such as NIH, NSF, DOE and, more recently, EPA. Now funding of basic science has grown to the point where many question the balance between such basic research and the traditional problem-solving applied research in the AES.

The decline in state- and USDA-originated funding comes at a particularly crucial time in California. Agriculture and related in-

* Vernon Ruttan and Robert Evenson, economists at the University of Minnesota and Yale University, respectively. dustries, the largest single sector of the California economy, now face unprecedented challenge. Rapid population growth is creating intense competition for land and water resources. Environmental regulation of pesticides and other chemically-based technologies is tightening. Deteriorating air quality threatens crop yields in some parts of the state. California agricultural products are meeting intense competition in both domestic and foreign markets.

If the agricultural sector is to remain viable in the California economy and competitive in domestic and foreign markets, adjustments will be necessary. Scientists must generate new technology which not only enhances production, but safeguards the environment and natural resources.

What strategies and actions are now needed to ensure a balanced, forward-looking, and responsive agricultural research system?

- The research and education community must build public support and prove its readiness to address critical state research needs. The critical research needs of thefuture areinterrelated and will involve the joint interests of agriculture, natural resources, and the environment. All Californians stand to gain.

- The AES must restate its missions in light of agriculture's relationship to natural resources and the environment; set and communicate its priorities through a transparent process involving both scientists and publicinterest groups; and prepare to organize, coordinate, and deploy scarce resources across the continuum of basic to applied research.

- Colleges of agriculture and the AES must give greater emphasis to interdisciplinary, mission-oriented research whether through consolidation of departments or formation of cross-disciplinary research entities. Scientist reward systems should be reformed to give greater weight to such research and also to applied and problem-solving research conducted with experiment station funds.

- Some research now conducted in the AES could be shifted to the private sector, where spending on agricultural research now exceeds that of the public sector. In addition, Cooperative Extension's (CE) applied, problem-solving research capabilities should be increased. Linkage between CE and the AES, with leadership assigned to department-based CE specialists, should be tightened and reinforced by appropriate rewards to participating scientists.

- Private sector support of the AES should be increased, particularly for applied and problem-solving research. This support now constitutes about $16 \%$ of the total AES budget. The $\$ 23$ million in private sector support in 1990 represents a tiny fraction of the state's agricultural income of $\$ 17$ billion. In return for increased support, the private sector will reasonably expect clear commitments from the AES and an efficient, reliablesystem of information transfer.

After a decade of virtually no real growth in funding for agricultural research, there is a clear need to increase public and private investment in research if the interrelated problems of agriculture, natural resources, and environmental quality are to be addressed. For this tooccur, theexperimentstation itself must proveits readiness to address critical research needs by restating and refocusing its historic missions. 